\title{
Perceived self-efficacy in teamwork and entrepreneurship in university students. A gender study
}

\author{
Jesús Enrique Peinado Pérez, María del Carmen Zueck Enríquez, Gabriel Gastélum Cuadras, \\ Yunuen Rangel Ledezma, Humberto Blanco Vega*
}

Faculty of Physical Culture Sciences, Autonomous University of Chihuahua, Chihuahua, México

Email address:

hblanco@uach.mx (H. B. Vega)

\section{To cite this article:}

Jesús Enrique Peinado Pérez, María del Carmen Zueck Enríquez, Gabriel Gastélum Cuadras, Yunuen Rangel Ledezma, Humberto Blanco Vega. Perceived Self-Efficacy in Teamwork and Entrepreneurship in University Students. A Gender Study. Science Journal of Education.

Vol. 3, No. 1, 2015, pp. 1-5. doi: 10.11648/j.sjedu.20150301.11

\begin{abstract}
The purpose of the present study was comparing the profiles of perceived self-efficacy in teamwork and entrepreneurship between men and women university students. A total sample of 2,089 participants, 902 women and 1,187 men, aged 17-20 years participated in this study. All the freshmen university students from each degree offered by the Autonomous University of Chihuahua (Mexico) conformed the sample. In order to carry out the study it was used a quantitative approach with a descriptive and transversal survey design. All the participants completed the Self-efficacy Teamwork and Entrepreneurship Scale. Statistically, the results of the one-way multivariate analysis of variance, followed by the one-way univariate analyses of variance, showed that women have a significant $(\mathrm{p}<.05)$ and better perceived self-efficacy in teamwork than men, in the desired self-efficacy and reachable self-efficacy, but statistically in the possibility for improving self-efficacy perceived significant differences were not found $(\mathrm{p}>.05)$. Regarding the entrepreneurship factor, females results showed a significant greater desire and reachable self-efficacy than men $(\mathrm{p}<.05)$. However, for all the other variables statistically significant, differences were not found $(\mathrm{p}>$.05). Thanks to differences found between men and women in their own perception of self-efficacy, it's suggested that in order to design an intervention to improve the perceived self-efficacy of the students, the variable gender should be taken into account.
\end{abstract}

Keywords: Student's Beliefs, Gender Differences, Higher Education, Academic Performance, Student Characteristics

\section{Introduction}

The behavior of the people, according to Bandura [1], can be better predicted by the beliefs that individuals have about their own capabilities, since these perceptions contribute to outline what people do with the skills and knowledge they have $[2,3]$. This self-perception, called self-efficacy, has a deeply influence on the choice of tasks and activities, in the effort and perseverance of people when face certain challenges and even experiencing emotional reactions to difficult situations [4]. In short, self-efficacy beliefs represent a cognitive mechanism that is between knowledge and action, and defining it along with other variables, the success of one's actions $[5,6]$.

As an example of the importance of self-efficacy in academic settings, we can say that this reveals why people with the same level of skill and knowledge have behaviors and/or different results, or why people act in dissonance with their skills [7, 8]. This is because the appropriate academic performance also depends on the perceived efficacy to manage academic demands successfully. Therefore, self-efficacy beliefs in one's ability are essential to master academic activities; as students who trust their abilities are more motivated to achieve their goals [9]. Likewise, people who doubt their capabilities can believe that things are more difficult than they really are a belief that generates stress, depression and a narrow view to solve problems [4]. It has been shown that a low level of self-efficacy can be responsible, not only for declining school performance and interest in the study, but also youth people don't modify their behaviors, hence the importance of education to strengthen the development of academic competence in students and encourage skills that enable believe in their own abilities $[5,6]$.

According to the results of previous research studies [10-13], it seems that the gender differences in the perceived self-efficacy may be due to the different ways in which men 
and women experience each of the four sources of the self-efficacy. In this line, considering the achievements of earlier performance as one of the most important sources of self-efficacy, it can be seen that boys are exposed to a wider range of experiences in a greater number of areas outside the home, while girls are traditionally exposed to a greater number of experiences inside the home. Based on a process of differential gender socialization, this differential exposure to each of the sources of self-efficacy might allow women to develop a lower self-efficacy than men for typically masculine tasks. Hence, the gender differences in the academic motivation can be better explained by the beliefs that students have about their own attributes of their gender than by inherent variables to the gender itself.

In this line, previous studies found that the self-efficacy beliefs act as moderators of the gender differences in the degree choices, courses, and occupations [14, 15]. Therefore, unlike men who show consistency in their estimates of self-efficacy, women tend to have lower perceptions of traditionally masculine occupations than of those that are traditionally female's [16]. Unfortunately, to our knowledge there are no studies examining the influence of gender in teamwork and entrepreneurship. Consequently, the purpose of the present study was to compare the profiles of perceived self-efficacy in teamwork and entrepreneurship between men and women university students. The results of the present study might provide knowledge that would help to find out how to promote educational interventions within an educational perspective for attention to the diversity in the classroom.

\section{Method}

\subsection{Participants and Design}

Table 1. Subject distribution according to academic field and gender.

\begin{tabular}{llll}
\hline \multirow{2}{*}{ Academic Field } & Gender & \multirow{2}{*}{ Total } \\
\cline { 2 - 3 } & Female & Male & \\
\hline Physical Education & 81 & 214 & 295 \\
Education and Liberal Arts & 96 & 72 & 168 \\
Health Sciences & 121 & 108 & 229 \\
Administration and Social Sciences & 176 & 124 & 300 \\
Political Sciences & 200 & 89 & 289 \\
Engineering and Technology & 143 & 449 & 592 \\
Farming Sciences & 85 & 131 & 216 \\
Total & 902 & 1,187 & 2,089 \\
\hline
\end{tabular}

A sample of 2,089 university students, 902 women and 1,187 men, aged 17-20 years $(\mathrm{M}=18.23$; $\mathrm{SD}=.74)$ participated in the present study. The sample was aswered by all the freshmen university students from each degree offered by the Autonomous University of Chihuahua (Mexico). A convenience sampling was used in order to try to cover the representation of all the degrees (Table 1). Regarding the design of the study, a quantitative approach with a descriptive and transversal survey design was used [17]. The independent variable was gender (women and men) and the dependent variables were the mean scores in the four scenarios in both teamwork and entrepreneurship.

\subsection{Instrument}

Self-efficacy in teamwork and entrepreneurship was measured by the Self-efficacy Teamwork and Entrepreneurship Scale [18]. This questionnaire consists on a 16-item scale with two subscales: teamwork ( 8 items) and entrepreneurship ( 8 items). According to previous studies [3, 19], in the present study a Likert-type scale from 0 to 10 was chosen for the present study due to the fact that in the Mexican academic context students are commonly assessed by a scale from 0 to 10,. For each domain (item) of the teamwork and entrepreneurship competences (subscales), the participants were asked about how capable they feel, how much interest they have, and if they would make an effort to change how capable they will be to... Therefore, all the participants responded to each of the 16 items of the questionnaire in the three different scenarios: (a) Scenario of perceived ability, responding in the context "how capable I feel to... to manage in each of the domains of the competences above mentioned"; (b) Scenario of interest in being able, responding in the context "how much interest I have in being able to... to manage in each of the domains of the competences above mentioned"; and (c) Scenario of change to be able to, responding within the context "if I would make an effort to change, how capable I will be able to... to manage in each of the domains of the competences above mentioned".

When calculating the scores for both dimensions, problem solving and scientific communication, four different values were calculated: (1) Perceived self-efficacy, obtained from the average scores in the scenario of perceived ability; (2) Desired self-efficacy, calculated from the average scores in the scenario of interest of being able; (3) Reachable self-efficacy, obtained from the mean scores in the scenario of being able; and (4) Possibility of improvement in the perceived self-efficacy, calculated from the mean difference between reachable self-efficacy and perceived self-efficacy. A higher score indicates greater self-efficacy, whereas a lower score represents lesser self-determination. The Self-efficacy Teamwork and Entrepreneurship Scale demonstrated adequate psychometric properties (GFI $=.859$; RMSEA $=.096$; Cronbach coefficient alphas $=.916$ and .932 for teamwork and entrepreneurship, respectively) [18]. Finally, the internal consistency reliability of the teamwork factor was very high: perceived self-efficacy .915 (.909-.920), desired self-efficacy .923 (.918-.928) and reachable self-efficacy .931 (.926-.935).

\subsection{Procedure}

All the freshmen university students from each degree offered by the Autonomous University of Chihuahua in the semester January-June of 2012 were invited to participate in the present study. These university students were fully informed about all the features of the project. Then, all the students that had agreed to participate were asked to sign a 
written inform consent. After the students' approvals were obtained, participants completed the above mentioned questionnaire by means of the instrument module administrator of the Scales Editor Version 2.0 [20].

Participants completed the questionnaire in the computer rooms of their faculties during a session. At the beginning of the session the researchers gave a general introduction about the importance of the research and how to access the questionnaire thought the software. When the participants were in the editor, the instructions about how to fill out the questionnaire correctly appeared before the instrument. Additionally, the participants were advised to ask for help if confused concerning either the instructions or the clarity of a particular item. Completion of the entire questionnaire took approximately 30 minutes. At the end of the session their participation was welcomed. Afterward, when all the participants completed the questionnaire, the data were collected by means of the results generator module of the Scales Editor Version 2.0 [20].

\subsection{Data Analysis}

Descriptive statistics (means and standard deviations) for all the variables were calculated. Subsequently, after verifying that the data met the assumptions of parametric statistical analyses, a one-way multivariate analysis of variance (MANOVA), followed by the one-way univariate analysis of variance (ANOVA), were used to examine the differences between men and women in both, reported self-efficacy in teamwork and entrepreneurship scores. Moreover, the effect size was estimated using the eta-squared $(\eta 2)$. The internal consistency reliability of the each variable was estimated using the Cronbach coefficient alphas (ICC) and the 95\% confidence intervals (CI). All statistical analyses were performed using the SPSS version 20.0 for Windows (IBM ${ }^{\circledR}$ SPSS $®$ Statistics 20$)$. The statistical significance level was set at $\mathrm{p}<.05$.

\section{Results}

\subsection{Teamwork Factor}

Table 2 shows the mean values and standard deviations of the self-efficacy in teamwork, as well as the results of the MANOVA and the follow-up univariate ANOVAs. The MANOVA results indicated overall statistical significant differences between genders in the self-efficacy in teamwork scores (Wilks' $\lambda=.987 ; \mathrm{p}=.01 ; \eta^{2}=.013$ ). Afterward, statistically the follow-up ANOVAs showed that women have a significant and better perceived self-efficacy in teamwork than men $(\mathrm{F} 1=13.711 ; \mathrm{p}<.001)$, in the desired self-efficacy $(\mathrm{F} 1=25.186 ; \mathrm{p}<.001)$ and reachable self-efficacy $(\mathrm{F} 1=$ 23.676; $<<.001)$. However, statistically in the possibility for improving self-efficacy perceived significant differences were not found $(\mathrm{p}>.05)$.

Table 2. MANOVA results for gender differences in the four self-efficacy indexes for the teamwork factor.

\begin{tabular}{|c|c|c|c|c|c|}
\hline & Women $(n=902)$ & $\operatorname{Men}(n=1187)$ & $\mathbf{F}$ & $\mathbf{p}$ & $\eta^{2}$ \\
\hline & & & 9.053 & .01 & .013 \\
\hline Perceived self-efficacy & $8.02(1.22)$ & $7.81(1.36)$ & 13.711 & $<.001$ & .007 \\
\hline Desired self-efficacy & $8.85(1.11)$ & $8.58(1.28)$ & 25.186 & $<.001$ & .012 \\
\hline Reachable self-efficacy & $9.10(0.97)$ & $8.87(1.12)$ & 23.676 & $<.001$ & .011 \\
\hline Possibility for improving perceived self-efficacy & $1.08(0.77)$ & $1.06(0.87)$ & 0.163 & .686 & .000 \\
\hline
\end{tabular}

Note. Descriptive values are reported as mean (standard deviation)

\subsection{Entrepreneurship Factor}

Table 3 shows the mean values and standard deviations of the self-efficacy in entrepreneurship, as well as the results of the MANOVA and the follow-up univariate ANOVAs. The MANOVA results indicated overall statistical significant differences between genders in the self-efficacy in entrepreneurship scores (Wilks' $\lambda=.994 ; \mathrm{p}=.006 ; \eta^{2}=.006$ ). Afterward, statistically the follow-up ANOVAs showed that women present reported have a significant and greater desire and reachable self-efficacy in entrepreneurship than men (F1 $=9.767 ; \mathrm{p}=.002$, and $\mathrm{F} 1=6.680 ; \mathrm{p}=.009$, respectively). However, statistically significant differences in the perceived self-efficacy and the possibility to improve self-efficacy were not found $(\mathrm{p}>.05)$. Finally, the internal consistency reliability of the entrepreneurship factor was very high: perceived self-efficacy .929 (.924-.934), desired self-efficacy .933 (.929-.937) and reachable self-efficacy .938 (.934-.942).

Table 3. MANOVA results for gender differences in the four self-efficacy indexes for the entrepreneurship factor.

\begin{tabular}{|c|c|c|c|c|c|}
\hline & Women $(n=902)$ & $\operatorname{Men}(n=1187)$ & $\mathbf{F}$ & p & $\eta^{2}$ \\
\hline & & & 4.055 & .006 & .006 \\
\hline Perceived self-efficacy & $7.82(1.36)$ & $7.75(1.38)$ & 1.337 & .248 & .001 \\
\hline Reachable self-efficacy & $9.03(1.04)$ & $8.90(1.08)$ & 6.680 & .009 & .003 \\
\hline Possibility for improving perceived self-efficacy & $1.21(0.92)$ & $1.16(0.93)$ & 1.673 & .196 & .001 \\
\hline
\end{tabular}

Note. Descriptive values are reported as mean (standard deviation) 


\section{Discussion and Conclusions}

The purpose of the present study was to compare the profiles of perceived self-efficacy in teamwork and entrepreneurship between men and women university students.

The teamwork factor refers basically to be able to respect and be flexible to tolerate divergent thinking to reach agreement by consensus; interact in multidisciplinary groups; identify potential leadership skills and group development and participate in the development and implementation of plans and projects through teamwork. As regards the results of this study, though no differences in the possibility for improving self-efficacy between men and women were found, women perceived themselves with greater perceived, desired and reachable self-efficacy in teamwork than the men.

Furthermore, the entrepreneurship factor refers to being able to demonstrate capacity to generate employment and self-employment; link academic environment with the work environment; create and innovate; best use of existing resources and use the principles of strategic management in the development of projects. As regards the results of this study, though no differences in the perceived and the possibility to improve self-efficacy between men and women were found, women perceived themselves with greater desire and reachable self-efficacy in entrepreneurship than men.

Saunders, Davis, Williams, and Williams [21] carried out a research study on the differences in academic self-efficacy between boys and girls among high school students. Similarly to the results of the current study, these authors found that girls presented higher levels of academic self-efficacy than men and greater desires of finishing their studies. On the other hand, in addition to the results obtained in this research, over the last few years a few theoretical bases have served as a framework to explain the vocational behavior of men and women. Among these theories, the Bandura's [22] theory of self-efficacy should be highlighted, according to which the self-efficacy expectations are one of the main determinants of gender differences in the academic and professional decisions-making. These differences are the result of the socialization process that leads men and women to have a different perception about the tasks, activities, studies and occupations that are most appropriate for each gender. Therefore, under the implicit assumption that the promotion of self-efficacy will serve as a vehicle for improving other positive outcomes such as the academic achievement and self-esteem, improving the perception of being able to learn is a valuable educational objective. Additionally, it should be taken into account that the continued sense of failure reduces the success expectations and it does not favor any form of either personal learning or personal development [23].

In conclusion, the main finding of the present study is that, women perceived themselves with greater perceived, desired and reachable self-efficacy in teamwork than men. Additionally, the women perceived themselves with greater desired and reachable self-efficacy in entrepreneurship than the men. These differences found between men and women regarding their perceptions of self-efficacy suggest that when designing any kind of educational intervention aimed at the improvement of self-efficacy, the gender of the individual should be taken into account. The results of the present study might provide knowledge that helps to find out how to promote educational interventions within an educational perspective for attention to the diversity in the classroom. Finally, the importance of carrying out future research studies about this topic among Mexican students in order to expand the knowledge in this field should be highlighted.

\section{Acknowledgements}

This study is part of a project funded by the Secretaría de Educación Pública-Subsecretaría de Educación Superior-Dirección General de Educación Superior Universitaria de México [Mexican Ministry of Education-Department of Higher Education-General Directorate of the University Education] (OF-13-6894).

\section{References}

[1] A. Bandura, Self-efficacy: The exercise of control, Freeman, New York, 1997.

[2] D.A. Adeyemo, Moderating influence of emotional intelligence on the link between academic self-efficacy and achievement of university students, Psychology Developing Societies, Vol. 19, pp. 199-213, 2007.

[3] H. Blanco, M. Martínez, M.d.C. Zueck, G. Gastélum, Análisis psicométrico de la escala autoeficacia en conductas académicas en universitarios de primer ingreso, Actualidades Investigativas en Educación, Vol. 11, pp. 1-27, 2011.

[4] M. Vera, M. Salanova, B. Martín-del-Río, Self-efficacy among university faculty: How to develop an adjusted scale, Anales de Psicología, Vol. 27, pp. 800-807, 2011.

[5] M.Á. Carbonero, E. Merino, Autoeficacia y madurez vocacional, Psicothema, Vol. 16, pp. 229-234, 2008.

[6] M. Ornelas, H. Blanco, J.M. Rodríguez, F.J. Flores, Análisis psicométrico de la escala autoeficacia en conductas de cuidado de la salud física en universitarios de primer ingreso, Formación Universitaria, Vol. 4, pp. 21-34, 2011.

[7] A. Bandura, Self-efficacy mechanism inhuman agency, American Psychologist, Vol. 37, pp. 122-147, 1982.

[8] E. Pérez, C. Lescano, D. Heredia, P. Zalazar, L. Furlám, M. Martínez, Desarrollo y análisis psicométricos de un inventario de autoeficacia para inteligencias múltiples en niños argentinos Psicoperspectivas, Vol. 10, pp. 169-189, 2011.

[9] Á. Blanco, Creencias de autoeficacia de estudiantes universitarios: Un estudio empírico sobre la especificidad del constructo, RELIEVE, Vol. 16, pp. 1-28, 2010.

[10] C. Asbún, Y. Ferreira, Autoeficacia profesional y género en adolescentes de cuarto de secundaria de la zona sur de la ciudad de la paz, Revista Ajayu, 2004. 
[11] N.E. Betz, G. Hackett, A self-efficacy approach to the career development of women, Journal of Vocational Behavior, Vol. 18, pp. 326-339, 1981.

[12] G. Hackett, Self-efficacy in career choice and development, in: A. Bandura (Ed.) Self-efficacy in changing societies, Cambridge University Press, New York, 1995, pp. 232-258.

[13] F. Pajares, Self-efficacy beliefs in academic settings, Review of Educational Research, Vol. 66, pp. 543-578, 2001.

[14] F.H. Borgen, N.E. Betz, Career self-efficacy and personality: Linking career confidence and the healthy personality, Journal of Career Assessment, Vol. 16, pp. 22-43, 2008.

[15] F.H. Borgen, N.E. Betz, Integrating self through personality, interests, and self- efficacy, in: P.J. Hartung, L.M. Subich (Eds.) Developing self in work and career: Concepts, cases, and contexts, APA Books, Washington, DC, 2011, pp. 141-160.

[16] N.E. Betz, The career development of women, in: F. Denmark, M.A. Paludi (Eds.) Psychology of women: A handbook of issues and theories, Greenwood Press, Westport, CT, 2007, pp. 717-752.

[17] R. Hernández, C. Fernández, P. Baptista, Metodología de la investigación, McGraw- Hill, México, 2010.
[18] G. Gastélum, J.C. Guedea, J. Viciana, J.E. Peinado, Composición factorial de una escala de autoeficacia en el ámbito del trabajo en equipo y liderazgo en universitarios de ciencias de la salud, Formación Universitaria, Vol. 5, pp. 49-60, 2012.

[19] J. Viciana, E.M. Cervelló, J. Ramírez, Effects of manipulating positive and negative feedback on goal orientation, perceived motivational climate, satisfaction, task choice, perception of ability, and attitude to physical education lessons, Perceptual and motor skills, Vol. 105, pp. 67-82, 2007.

[20] H. Blanco, M. Ornelas, J.L. Tristán, A. Cocca, D. Mayorga-Vega, J. López-Walle, J. Viciana, Editor for creating and applying computerise surveys, Procedia Social and Behavioral Sciences, Vol. 106, pp. 935-940, 2013.

[21] J. Saunders, L. Davis, T. Williams, J.H. Williams, Gender differences in self perceptions and academic outcomes: A study of african-american high school students, Journal of Youth and Adolescence, Vol. 33, pp. 81-90, 2004.

[22] A. Bandura, Autoeficacia: Como afrontamos los cambios de la sociedad actual, Desclée de Brouwer, S. A., Madrid, 1999.

[23] M. Ornelas, H. Blanco, G. Gastélum, A. Chávez, Autoeficacia percibida en la conducta académica de estudiantes universitarias, Formación Universitaria, Vol. 5, pp. 17-26, 2012. 